\title{
AN ELECTRICITY PRICE-DEPENDENT CONTROL-LIMIT POLICY FOR CONDITION- BASED MAINTENANCE OPTIMIZATION FOR POWER GENERATING UNIT
}

\section{ZASTOSOWANIE STRATEGII UZALEŻNIAJĄCEJ TERMIN PRZEGLĄDU OD CENY PRĄDU ELEKTRYCZNEGO DO OPTYMALIZACJI UTRZYMANIA RUCHU AGREGATU PRĄDOTWÓRCZEGO Z UWZGLĘDNIENIEM JEGO STANU TECHNICZNEGO}

\begin{abstract}
For the control-limit policy of condition-based maintenance (CBM), it usually focuses on the internal condition of the equipment while neglecting the un-constant external conditions. However, the electricity price-dependent downtime cost have influence on the cost-effectiveness of control-limit policy for a generating unit in a power system. To make a linkage between CBM and the nonconstant cost model, an electricity price-dependent control-limit policy (EPCLP) is proposed to accommodate the time-dependent downtime costs. For the proposed EPCLP, preventive maintenance control-limits is much flexible to be adjusted to different electricity price levels, and the maintenance cost reduction can be achieved among the planning horizon as a result. The optimal control-limits and maintenance costs for different downtime-cost ratios, reliabilities, covariate processes and electricity price scenarios are analysed to compare the performances between the proposed policy and the constant control-limit policy. Through the sensitivity analysis, the application scope of the proposed policy is evaluated.
\end{abstract}

Keywords: Power generating unit, Multi-component system, Condition-based maintenance, Control-limit policy, Electricity price.

\begin{abstract}
Stosując strategie utrzymania ruchu uwzględniajace bieżacy stan techniczny obiektu (condition based maintenance, CBM) oparte na pojęciu progu konserwacji koniecznej (control limit), najczęściej przywiąuje się wagę do stanu samego sprzętu, ignorując przy tym niestałe warunki zewnętrzne. Należy jednak pamiętać, że w przypadku agregatów pradotwórczych wchodzacych w sktad uktadów elektroenergetycznych, koszty przestoju zależne od ceny energii elektrycznej maja wpływ na opłacalność stosowania strategii progu konserwacji koniecznej. Aby powiąać CBM z modelem kosztów niestałych, zaproponowano strategię progu konserwacji koniecznej, w której wysokość progu uzależniona jest od ceny prądu elektrycznego (electricity price-dependent control-limit policy, EPCLP). Przyjęcie takiej strategii pozwala uwzględnić koszty przestojów zależne od czasu. W EPCLP, progi czasowe konserwacji zapobiegawczej sa bardzo elastyczne, co pozwala na ich regulację zgodnie z aktualna cena energii elektrycznej. Strategia umożliwia redukcje kosztów w danym horyzoncie planowania. W celu porównania proponowanej strategii ze strategia stałego progu konserwacji koniecznej, w pracy przeanalizowano optymalne progi czasowe konserwacji koniecznej oraz koszty utrzymania ruchu dla różnych stosunków przestoju do kosztu, różnych wartości niezawodności, różnych procesów kowariantnych oraz różnych scenariuszy zmian cen energii elektrycznej. Zakres zastosowania proponowanej strategii oceniano za pomoca analizy czułości.
\end{abstract}

Stowa kluczowe: agregat prądotwórczy, system wieloelementowy, utrzymanie zależne od bieżacego stanu technicznego, strategia progu konserwacji koniecznej, cena energii elektrycznej.

\section{Introduction}

Preventive maintenance (PM) is important for the operation of a generating unit to avoid deteriorations and catastrophic failures. Generally, there are two types of preventive maintenance strategies, i.e. scheduled maintenance and condition-based maintenance (CBM) $[1,14,17]$. For scheduled maintenance (also called planned maintenance), the PM is carried out in accordance with established time intervals. With rapid development of instrumentation and measurement technology, more efficient maintenance types are needed, such as condition-based maintenance (CBM). For CBM, the maintenance action taken at each inspection is determined once the state of the system is higher than the specified control-limit $[3,9,16]$. In the class of control-limit policy, maintenance decision is made by comparison of degradation level to the critical thresholds, e.g. in [3]. Furthermore, functional failure and potential failure was defined by the failure threshold in [16]. The problem of what PM control-limit should be and how it should be obtained has been an increasingly attractive research topic, e.g. in $[4,5,25]$.

The PM thresholds can be categorized into two main types corresponding to various system performance measures, such as a condition monitoring index and an integrated reliability index [14]. For the threshold based on a condition monitoring index [7, 24], the condition monitoring index can be obtained from monitoring items, such as wear, temperature, pressure, etc. For example in [24] the PM threshold was based on the wear measurement, while a kind of control-limit based on laser's operating current was studied in [7]. Another type of threshold is set on the integrated reliability index, and it is derived from both event data and condition monitoring data $[9,14]$. When the reliability of the assets is influenced and/or indicated by different risk factors, which are so-called covariates, the condition monitoring data can be extended to both environment covariates and condition monitoring covariates [9]. Most of the covariate models are developed based on the Proportional Hazards Model (PHM) [6] and more extended models can be referred to $[9,14]$. For example, a kind of 
PM threshold of control-limit policy (CLP) was proposed based on the PHM in [2]. A kind of preventive replacement threshold was proposed based on the deterioration level in presence of environmental covariates in [26].

Alternatively, dynamic control-limit policy, as a new kind of control-limit, has been applied to construct dynamic thresholds. It has been shown to have a cost-saving and a better generalization capability than conventional constant control-limit policy. The studies about dynamic control-limit policy can be classified mainly into three categories, such as inspection rate-dependent threshold [5], age-dependent threshold $[4,8,15]$ and degradation-dependent threshold [26]. For an inspection rate-dependent threshold [5], the higher the inspection rate, the higher the degradation-type PM threshold. It makes sense that more frequent inspections lead to more timely warning if system is near to failure. For an age-dependent threshold, PM threshold decreases in age and should be triggered by smaller signal values when it deteriorates [4]. The PM threshold can also be non-decreasing in age and it can be more tolerant of larger signal values for older systems, if there is increasing accuracy in predicting the future signal value [8]. For a degradation-dependent threshold, Zhao et al. [26] proposed an adaptive maintenance decision to take into account the state of covariates to dynamically adapt the PM threshold. However, much further improvements of dynamic control-limit policy are needed with respect to both internal condition (e.g. degradations) and un-constant external condition (e.g. non-constant cost), especially for the application of a generating unit.

In a power system, to raise the market competitiveness for a generating unit, not only the reliability should be improved, but the economical performance should be improved as well. Although most of the CBM decisions are made based on degradation condition, it is worth noting that the time-dependent downtime cost can occur for each maintenance and replacement action. During the maintenance duration, the downtime cost is an important part of the total maintenance cost. The downtime cost is fluctuant according to the time-dependent electricity price, since electricity price is the main influence factor for time-varying downtime cost. As a result, the problem needs to be addressed that how to further reduce the maintenance cost in terms of time-varying downtime cost for a generating unit.

Although control-limit policy is widely applied to conditionbased maintenance, existing control-limit policies do not examine the non-constant cost in CBM optimization. In terms of the CBM optimization based on cost criteria for a generating unit, the time-dependent electricity price can not be ignored since it can cause the fluctuation of downtime cost. However, the research about this problem is limited [2], so extended CLP considering non-constant cost is in needed of research. Inspired by the control-limit policy for CBM, we decide to make a linkage between non-constant cost and the control-limit policy for CBM. As a result, we extend the constant control-limit policy to an electricity price-dependent control-limit policy to deal with the electricity price-dependent downtime cost in CBM. In this paper, we consider the influence of both the degradation and the electricity price on the control-limit policy. Compared to CLP, the proposed EPCLP can take advantage of time-dependent electricity price in order to perform PMs economically to achieve the minimal maintenance cost, by assigning different thresholds to different electricity price levels. The proposed EPCLP can be much more flexible for a generating unit, in terms of both reliability and cost-effectiveness.

The rest of this paper is structured as follows: section 2 describes the proposed electricity price-dependent control-limit policy; in section 3, an extensive computational analysis is conducted for evaluation of the proposed EPCLP in a comparison to the constant CLP; concluding remarks are given in section 4 .

\section{Electricity price-dependent control-limit policy}

After symbols and abbreviations are listed in section 2.1, section 2 has three primary stages. In section 2.2 , the conventional controllimit policy is described before the proposed policy. Next, in section 2.3 , the structure of the proposed electricity price-dependent controllimit policy is illustrated, and the innovations and characteristics are proposed. And then, in section 2.4, the modelling and calculation procedures are described for CBM optimization in terms of the proposed policy.

\subsection{Symbols and abbreviations}

\section{Model parameter}

$h_{i} \quad$ hazard rate of component $i$

$\beta_{i}, \eta_{i} \quad$ Weibull shape parameters and scale parameters for component $i$

$a_{i t} \quad$ age of component $i$ at time $t$

$z_{i t} \quad$ covariate value of component $i$ at time $t$

$\gamma_{i} \quad$ corresponding coefficient of the covariate for component $i$

$e p_{t} \quad$ electricity price at time $\mathrm{t}$

$K_{i} \quad$ difference between the cost of per CM and the cost of per PM for component $i$

$C_{\mathrm{dL}}, C_{\mathrm{dH}}, C_{\mathrm{dM}}$ downtime cost during above-average, average and below-average electricity price periods respectively

$F_{i t} \quad$ probability of sudden failure at time $t$ for component $i$

$\Delta t \quad$ inspection interval

$c_{\mathrm{c} i}, c_{\mathrm{p} i}, c_{\mathrm{o} i} \quad$ cost for each CM, PM and OM, respectively

$c_{\mathrm{d} t} \quad$ downtime cost at time period $t$

$x \quad$ simulation scenario

$W_{x} \quad$ cost rate for simulation scenario $x$

Ns number of degradation simulations

$E(C) \quad$ expected cost rate

$\lambda \quad$ downtime cost ratio, i.e., DCR

$T_{\mathrm{cL}}, T_{\mathrm{cM}}, T_{\mathrm{cH}} \quad$ number of continuous periods for below-average price, average price and above-average price, respectively

$T_{\mathrm{sL}}, T_{\mathrm{sM}}, T_{\mathrm{sH}} \quad$ sum of the periods for below-average price, average price and above-average price, respectively

\section{Model variable}

$d_{1}\left(e p_{t}\right) \quad$ level-1 thresholds dependent on the electricity price at time $t$

$d_{1 \mathrm{H}}, d_{1 \mathrm{M}}, d_{1 \mathrm{~L}} \quad$ level-1 thresholds for above-average, average and below-average electricity price, respectively

$d_{2} \quad$ level-2 threshold

\author{
Abbreviations \\ PM Preventive Maintenance \\ CBM Condition-based Maintenance
}



$\mathrm{CM}$
Corrective Maintenance
$\mathrm{OM}$
Opportunistic Maintenance
PHM$$
\text { Proportional Hazards Model }
$$
SARIMA Seasonal Autoregressive Integrated Moving Average
CLP Control-limit policy
EPCLP Electricity price-dependent control-limit policy

\subsection{Control-limit policy}

A valuable statistical procedure for estimating the risk of equipment failure is the proportional hazard model (PHM) if it is subjected to condition monitoring [6]. A form of PHM combines a baseline hazard function $h_{0}$ along with a factor that takes into account covariates to improve the prediction of failure. In this paper, a Weibull PHM [14] is applied and it is calculated by Eq. (1). It is a joint model of PHM and Markov property for covariate evolution.

$$
h_{i t}=h_{0} \exp \left(\gamma_{i} z_{i t}\right)=\beta_{i}\left(a_{i t} / \eta_{i}\right)^{\beta_{i}-1} \exp \left(\gamma_{i} z_{i t}\right) / \eta_{i}
$$

where $\beta_{i}, \eta_{i}$ are Weibull shape parameters and scale parameters, respectively, for component $i$. $a_{i t}$ is the age of component $i$ at time $t, z_{i t}$ is the covariate value of component $i$ at time $t$, and $\gamma_{i}$ is the corresponding coefficient of the covariate.

A possible realization of the time evaluation of a component is illustrated in Fig. 1. For each component of a power generating unit, both sudden failure and degradation failure can occur [9]. Therefore, at each inspection time, there can be four possible events for each component, including CM, PM, OM or no maintenance actions. If the hazard $h_{i t}$ exceeds the predetermined control-limit levels, PM will be performed. If the multi-component system continues on operation without any maintenance action, covariate state of each component $i$ will follow the Markov process. Based on the state transition probability matrix we can obtain the sample covariates $z_{k+1}$ at next inspection based on the current value of covariates $z_{k}$. Covariates of each component can be selected by the EXAKT software [2]. For each component, the covariate state can be modelled by the Markov process $[13,18,19]$. The accumulated values of ppm metals behaved as a homogenous Markov process in [13], and a continuous time homogenous Markov process was modelled for the degradation state in [19]. The control-limit replacement policies for deteriorating systems were established by PHM which was dependent on its age and the condition monitoring state [18].

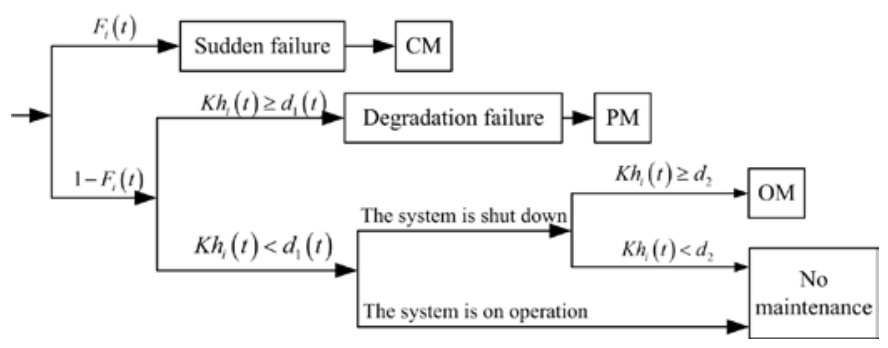

Fig. 1. Tree of possible events for component $i$ at time

\subsection{Structure of an electricity price-dependent control-limit policy}

To deal with the time-dependent downtime cost due to the fluctuating electricity price, we extend the PHM based CBM policy for multi-component system to an electricity price-dependent controllimit policy (EPCLP) from a constant control-limit policy (CLP). Instead of the constant control-limit, the threshold for the EPCLP is adjusted to different electricity price levels (e.g. above-average, aver- age and below-average). The level-1 thresholds $d_{1}$ are $d_{1 \mathrm{H}}, d_{1 \mathrm{M}}$ and $d_{1 \mathrm{~L}}$ for above-average, average and below-average electricity price, respectively, such that:

$$
\mathbf{d}_{1}\left(e p_{t}\right)= \begin{cases}d_{1 \mathrm{H}} & \text { if } e p_{t} \in\left(e p^{\mathrm{m}}+\Delta e p, e p^{\mathrm{U}}\right] \\ d_{1 \mathrm{M}} & \text { if } e p_{t} \in\left[e p^{\mathrm{m}}-\Delta e p, e p^{\mathrm{m}}+\Delta e p\right] \\ d_{1 \mathrm{~L}} & \text { if } e p_{t} \in\left[e p^{\mathrm{L}}, e p^{\mathrm{m}}-\Delta e p\right)\end{cases}
$$

where $e p^{\mathrm{U}}, e p^{\mathrm{L}}$ are the upper and lower bound of electricity price, respectively. Meanwhile, $e p^{\mathrm{m}}+\Delta e p, e p^{\mathrm{m}}-\Delta e p$ are the upper and lower bound of average level for electricity price, respectively.

The proposed EPCLP for CBM for a hydro generating unit as a multi-component system is proposed as follows:

1) For component $i$, perform CM if a sudden failure occurs with the probability $F_{i t}$.

2) For component $i$, perform PM if $K_{i} h_{i t} \geq d_{1}\left(e p_{t}\right)$;

3) If the system is shut down for the maintenance (e.g. PM or $\mathrm{CM}$ ), perform OM on the component $l$ if $K_{l} h_{l l}>d_{2}$.

A schematic representation of the EPCLP is presented in Fig. 2 to illustrate the cost-effectiveness of the proposed policy, compared to the constant CLP. For simplicity, the example describes a singlecomponent system instead of a multi-component system. As the hazard rate of the component increases from the initial time or after each maintenance, it can meet $d_{\mathrm{L}}<d$ (respectively, $d_{\mathrm{H}}>d$ ) during the low (respectively, high) price periods. Here, $d_{\mathrm{L}}, d_{\mathrm{H}}, d_{\mathrm{M}}$ are threshold for EPCLP, while $d$ is the constant threshold. As a result, PM can be performed during low price periods with much higher probability by EPCLP compared to the constant CLP. So the downtime cost is in total $\left(C_{\mathrm{dH}}+C_{\mathrm{dH}}+C_{\mathrm{dM}}\right)$ for the constant CLP, while the downtime cost is in total $\left(C_{\mathrm{dL}}+C_{\mathrm{dH}}+C_{\mathrm{dM}}\right)$ for EPCLP. The proposed policy can achieve a cost-reduction of $\left(C_{\mathrm{dH}^{-}} C_{\mathrm{dL}}\right)$ compared to the constant CLP in this example, since EPCLP is more flexible than CLP. From the illustration, EPCLP can be cost-efficient by balancing the timing of the outages, as well as by balancing the PMs and CMs.

However, for the trade-off among the costs of PM, CM and outages to achieve a minimal cost for the EPCLP, PM cannot necessarily be performed during below-average price periods with high probability for all cases. The problem is complicated since optimal thresholds are

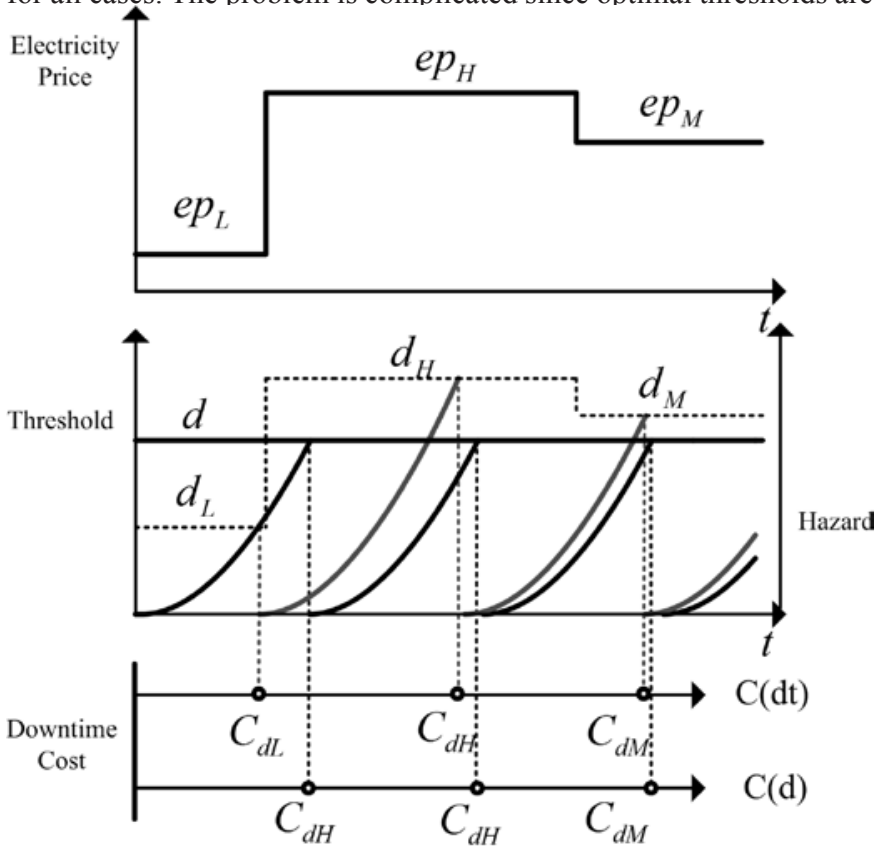

Fig. 2 Schematic representation of the epclp compared to clp 
sensitive to both the reliabilities of the multi-component system and the relationships between the various costs, as well as the degradation process and electricity price scenarios.

Qualitatively, for cases with high reliability levels and less number of above-average price periods, it can be cost-efficient to perform PM during above-average price periods, since the PMs and outages can be reduced effectively. While for cases with low reliabilities and a large number of above-average price periods, it would be cost-efficient to perform PM during high price periods.

When the downtime cost is higher, it could be cost-effective to perform fewer PMs, more CMs and fewer outages. So the threshold can be lower for the below-average electricity price level with fewer continuous periods. Conversely, if the downtime cost is lower, it could be cost-efficient to perform more PMs with fewer CMs. So the threshold of the electricity price level which has more continuous periods may be much lower. The advantage of the proposed policy in terms of the cost-efficiency can be verified by the results of the simulations in section 3.3.

However, for cases with much higher reliabilities, or with much lower downtime costs, the advantage of the proposed policy is not so significant. For cases with much higher reliabilities, few PMs are needed, so the cost-saving of EPCLP can be insignificant, the same goes for the cases with much lower downtime costs. Sensitivity analysis will be proposed in Section 3.3.

\subsection{Modelling of an electricity price-dependent control- limit policy for CBM}

Since the failure cost is generally much higher than that of performing PM, sufficient PMs can reduce failures but cost will be increased as well. So a trade-off exists between the scheduling of PMs and CMs. The objective of the problem is to obtain the optimal PM/ $\mathrm{OM}$ thresholds to minimize the average cost of maintenance and loss due to downtime during the planning horizon.

Based on these explanations, the EPCLP can be stated as follows: given the fluctuating electricity price, with having the stochastic degradation process and the relations specifying the permissible of maintenance actions, the problem is to the assign the dynamic thresholds to PMs and OMs, and the maintenance cost rate is minimized. The assumptions used in this problem are as follows:

1) The component degradation process can be described by the proportional hazard model, with covariates observable at each inspection.

2) The components of the system are independent in degradations and failure processes.

3) The components are economically dependent. The loss of productivity during downtime is incurred if the generating unit is shut down for CM or PM. The loss of productivity is incurred only once for each outage.

4) We focus on the maintenance optimization in this study, so the inspection interval is not a design variable in the optimization problem. The inspections are assumed to be scheduled according to fixed intervals, so we can assume they are performed at zero cost.

5) Each component may suffer random failure only once during each inspection interval. A failure may happen during the inspection interval or just at the inspection time. For simplification, we assume failures just occur at the inspection time, and so do the maintenance actions.

6) During downtime the components do not deteriorate.

7) Both CM and PM can fully recover the component to an asgood-as-new condition. lows:

$$
\begin{aligned}
& E C=\min _{\mathbf{d}_{1}\left(e p_{t}\right), d_{2}} \sum_{x=1}^{N s} p_{x} W_{x}\left(\mathbf{d}_{1}\left(e p_{t}\right), d_{2}\right) \\
& W_{x}\left(\mathbf{d}_{1}\left(e p_{t}\right), d_{2}\right)=\frac{1}{N T \cdot \Delta t} \sum_{t=1}\left(\sum_{i=1}^{N C}\left(I_{\mathrm{c} i t}^{x} c_{\mathrm{c} i}+I_{\mathrm{p} i t}^{x} c_{\mathrm{p} i}+I_{\mathrm{o} i t}^{x} c_{\mathrm{o} i}\right)+I_{\mathrm{d} t}^{x} c_{\mathrm{d} t}\right) \forall x \\
& \text { s.t. } \quad I_{\text {cit }}^{x}=\left\{\begin{array}{ll}
1 & \text { when } u_{i t}^{x}<F_{i t} \\
0 & \text { otherwise }
\end{array} \quad \forall i, t, x\right. \\
& I_{\mathrm{p} i t}^{x}=\left\{\begin{array}{ll}
1 & \text { when } I_{\mathrm{c} i t}^{x}=0 \& K h_{i t} \geq \mathbf{d}_{1}\left(e p_{t}\right) \\
0 & \text { otherwise }
\end{array} \forall i, t, x\right. \\
& I_{\mathrm{o} i t}^{x}=\left\{\begin{array}{l}
1 \quad \text { when } \prod_{i}^{N C}\left(1-I_{\mathrm{c} i t}^{x}\right)\left(1-I_{\mathrm{p} i t}^{x}\right)=0 \& \mathbf{d}_{1}\left(e p_{t}\right)>K h_{i t} \geq d_{2} \\
0 \quad \text { otherwise }
\end{array} \forall i, t, x\right.
\end{aligned}
$$

$$
\min _{1}\left(e p_{t}\right)>d_{2}
$$

$$
F_{i t}=1-\exp \left\{-h_{i t} \Delta t\right\}
$$

$$
u_{i t}^{x} \sim U(0,1)
$$

Eq. (3) is the objective function which indicates the purpose of identifying electricity price-dependent threshold sets that achieves the minimum expected maintenance cost over all possible degradation scenarios. Eqs. (4) state the maintenance cost rate for each degradation scenario $x$ over the whole planning horizon $N T$, including maintenance costs and downtime costs. Constraints (5) state a sudden failure will occur with the probability $F_{i t}$, and it can be determined by the stochastic variable $u_{i t}$. Constraints $(5) \sim(7)$ determine whether $\mathrm{CM}$, $\mathrm{PM}$ and $\mathrm{OM}$ will occur respectively for component $i$ during period $t$ for degradation scenario $x$. Constraints (8) guarantee the first-level thresholds be greater than the second-level threshold. Constraints (9) determine the sudden failure probabilities [23]. Constraints (10) impose the normal distribution on the stochastic variable $u_{i t}$.

Furthermore, to determine the value of PM threshold, the optimization of thresholds can be achieved by certain criteria such as cost, reliability and availability criteria. For example, an optimal PM threshold was derived by minimizing the average maintenance cost in $[2,18]$. A double-level PM threshold for a multi-component system was optimized on cost criteria as well in [23].

The proposed maintenance policy is evaluated by the average cost in the planning horizon, taking into account the cost of each type of maintenance action and downtime costs. In order to have sensible results, the maintenance cost evaluation is implemented using Monte Carlo simulation [22]. The simulation generates a large number of degradation scenarios. Each component undergoes stochastic transitions between the possible covariate states, evolving through conditions of availability and unavailability due to PM or sudden failure. For each simulation scenario $x$, the cost rate, including total maintenance cost and loss of productivity, will be calculated, denoted by $W_{x}$ if the thresholds, $\boldsymbol{d}_{1}\left(e p_{t}\right)$ and $d_{2}$, are given. The probability for each degradation scenario is $p_{x}$. After $N_{s}$ simulations, the expected cost rate $E C$ under given thresholds, $\boldsymbol{d}_{1}$ and $d_{2}$, can be estimated. The simulation procedures will continue until it satisfy the convergence criterion [20], and the number of valid simulations can be determined. The overall Monte Carlo simulation for EPCLP for a power generating unit is outlined in Fig. 3. 
Algorithm: Monte-Carlo simulation for EPCLP for a power generation unit Inputs: degradation process; price scenarios; $\mathrm{PHM}$ parameter.

Outputs: optimal threshold set for EPCLP.

Begin:

while $\left(\left(\boldsymbol{d}_{1}(\mathrm{ep}), d_{2}\right) \in\right.$ valid sets $)$ do

$n \leftarrow 1 ; t \leftarrow 1 ; i \leftarrow 1$;

while $\left(\left|\mathrm{E} C_{n}-\mathrm{E} C_{n-1}\right|>\right.$ tolerance limit $)$ do

while $(t<N T)$ do

while $(i \leqslant N C)$ do

generate $u \sim U(0,1) \quad$ // generation of sudden failure

if $u \leqslant F(i, t)$

then $f \mathrm{~cm}(i, t)=0$ and $\mathrm{Ccm} \leftarrow \mathrm{Ccm}+c_{\mathrm{cm}}(i)$ otherwise $f \mathrm{~cm}(i, t)=1$ end while

$i \leftarrow 1$;

while $(i \leqslant N C)$ do // judgement of PM

if $f \mathrm{~cm}(i, t)=0$ and $K \mathrm{~h}(i, t) \geqslant d_{1}(e p(t))$

then $f \mathrm{pm}(i, t)=0$ and $\mathrm{Cpm} \leftarrow \mathrm{Cpm}+c_{\mathrm{pm}}(i)$ otherwise $f \mathrm{pm}(i, t)=1$ end while

$i \leftarrow 1$;

while $(i \leqslant N C)$ do // judgement of OM

if $\operatorname{prod}(f \mathrm{~cm}) * \operatorname{prod}(f \mathrm{pm})=0$ and $f \mathrm{pm}(i, t)=1$ and $K \mathrm{~h}(i, t) \geqslant d$ then $f \circ \mathrm{m}(i, t)=0$ and $\mathrm{Com} \leftarrow \mathrm{Com}+c_{\mathrm{om}}(i)$ otherwise $f \circ \mathrm{m}(i, t)=1$ end while

if $\operatorname{prod}(f \mathrm{~cm}) * \operatorname{prod}(f \mathrm{pm})=0$ then $\mathrm{Cd} \leftarrow \mathrm{Cd}+c_{\mathrm{d}}(e p(t))$

end while

recording the average cost for each simulation $\mathrm{E} C_{\mathrm{n}}$

$\mathrm{n}=\mathrm{n}+1$;

end while

end while

end

report the optimal threshold set

Fig. 3. Monte carlo simulation method for EPCLP for a power generating unit

\section{Computational experiments}

In summary, the proposed electricity price-dependent controllimit policy (EPCLP) is an enhancement of constant control-limit policy (CLP). The maintenance actions using EPCLP and CLP and the comparison results of these two kinds of policy are discussed in Section 3.2. In order to achieve better insight into the performance of the EPCLP for CBM in Section 3.3, EPCLP is compared with the CLP in terms of the following four factors, downtime cost ratios (Section 3.3-1), reliabilities of the multi-component system (Section 3.3-2), covariate processes (Section 3.3-3), electricity price scenarios (Section 3.3-4).

\subsection{Dataset}

We present a simulation study to illustrate the effectiveness of the proposed policy for a generating unit as a multi-component system. The capacity of the generating unit is set to be 25MW. PHM parameters, including a shape parameter, a scale parameter and a covariate parameter for each component, are listed in Table 1. The parameter $\gamma$ is the covariate parameter which indicates the degree of influence a covariate has on the hazard. The costs of various maintenance actions for each component are listed in Table 1, including costs for CM, PM and OM, and the unit of the each maintenance cost is $\$ 1000$. The possible values for $z_{i t}$ are $Z_{l}$, which represent selected covariate bands. In this example, the values are set to be $Z_{0}=0, Z_{1}=35, Z_{2}=60$ and $Z_{3}=85$ which represent the condition monitoring states. The state transition matrix of each component, listed in Table 2(a-c), is derived from a

Table 1. Parameters of proportional hazards model and CM, PM and OM cost for critical components

\begin{tabular}{||c|c|c|c|c|c|c|}
\hline component & $\begin{array}{c}\text { Shape } \\
\text { Parameter } \beta\end{array}$ & $\begin{array}{c}\text { Scale } \\
\text { Parameter } \eta\end{array}$ & $\begin{array}{c}\text { Covariate } \\
\text { Parameter } \gamma\end{array}$ & $\begin{array}{c}\text { CM cost } \\
(\$ 1000)\end{array}$ & $\begin{array}{c}\text { PM cost } \\
(\$ 1000)\end{array}$ & $\begin{array}{c}\text { OM cost } \\
(\$ 1000)\end{array}$ \\
\hline hydro turbine & 3 & 1000 & 0.060 & 213 & 24 & 12 \\
\hline generator & 2 & 1500 & 0.044 & 150 & 20 & 10 \\
\hline transformer & 3 & 800 & 0.053 & 210 & 24 & 12 \\
\hline
\end{tabular}


$\left.e p^{\mathrm{m}}-\Delta e p\right]$, respectively. $e p^{\mathrm{m}}$ represents the mean value of the expected foresting electricity price and is $\$ 52 / \mathrm{MWh}$ in this case. The parameter $\Delta e p$ is set to be $\$ 5 / \mathrm{MWh}$ to divide the forecasting electricity price into three different levels.

The thresholds $\left[d_{1}, d_{2}\right]=\left[d_{1 \mathrm{~L}}, d_{1 \mathrm{M}}, d_{1 \mathrm{H}}, d_{2}\right]$ are defined within the range $\left(\$ 1000 /\right.$ day) while the discretization accuracy $\left(\log _{10}\right)=0.5$ for each component. For simplification the unit of the threshold (\$1000/ day) will not be mentioned, and the values of the thresholds are all in logarithm scale (base 10) for the rest of the paper.

\subsection{Comparison of EPCLP and CLP for the Mean Forecasting Electricity Price}

To confirm the performance of the proposed policy, we take the (Table 3 ) show that the electricity price-dependent threshold $d_{1}=\left[d_{1 \mathrm{~L}}\right.$, $\left.d_{1 \mathrm{M}}, d_{1 \mathrm{H}}\right]$ is $[-1,-1,0]$. The thresholds of below-average and average price periods are much lower than that of above-average price periods. The minimum of the price-dependent thresholds, $\min \left(d_{1}\right)=-1$, is much lower than the constant threshold $d_{1}=-0.5$. Meanwhile, the maximum of the price-dependent thresholds $\max \left(d_{1}\right)=0$ is greater than the constant threshold. Compared to the constant CLP, more PMs can be performed by the proposed policy to reduce failures. Specifically, the policy, the average number of $\mathrm{CMs}$ is reduced to 1.3 from 2.2 , and the average number of outages is increased to 11.7 from 9.8. As a result, the average cost is reduced by $(960-890) / 960=7 \%$. The standard error of the estimated cost is around $\$ 5 /$ day and the standard error of the average number of the event (outage, CM, PM or OM) is 0.1 .

The optimal thresholds of the proposed policy make sense in this mean forecasting electricity price scenario for an example. The results average number of PMs is increased to 14.0 from 8.0 by the proposed

probability of the event (e.g., outage, CM, PM or OM) occurred at time $t$. The event probability can be approximately estimated by the percentage of times the event occurs at time $t$ over all the total simulations. For example, if the failure event at time $t$ occurs 100 times over a total of 3000 simulations, the probability of the failure is estimated to be $100 / 3000=3.3 \%$. Compared to the constant CLP, PM can be performed during below-average and average price periods with much higher probabilities by the proposed policy as shown in Fig. 4. Meanwhile, the probabilities of failure (or CM) by the EPCLP are generally lower than that of the constant CLP during the planning horizon. So this case shows that the number of failures can be reduced significantly by the proposed policy.

\subsection{Study Results and Discussions for Sensitivity Analysis for EPCLP}

1) Influence of downtime cost ratios (DCR)

To analyze the effect of different DCR to optimal EPCLP, DCR is defined by $\lambda=c_{\mathrm{d}} /\left(c_{\mathrm{d}}+c_{\mathrm{p}}+c_{\mathrm{c}}\right)$. Here, $c_{\mathrm{p}}$ is the average of $c_{\mathrm{p} i}, c_{\mathrm{c}}$ is the average of $c_{\mathrm{c} i}$ and $c_{\mathrm{d}}$ is the average of $c_{\mathrm{d} t}$. DCR increases with higher downtime cost while $c_{\mathrm{p}}$ and $c_{\mathrm{c}}$ are fixed. For the mean price scenario, the proposed policy can offer a $3 \%$ to $7 \%$ cost-saving over the CLP (Table 4) within the valid range of DCR $\lambda \leq 0.35$. As $\lambda$ increases from 0.12 to 0.35 , the number of CMs increases with the number of PMs. It can be cost-effective to reduce the outages by increasing CM for higher DCR. Therefore, CM is increasing, and number of PMs and outages are decreasing while $\lambda$ is increasing. For higher DCR (e.g. $\lambda>0.35$ ), EPCLP is no longer cost-effective since less PM is needed.

The valid DCR can be categorized into low and high downtime cost in terms of the different optimal thresholds. Thresholds $\boldsymbol{d}_{1}$ are $[-0.5,-1,0]$ and $[-1.5,0,0]$ for low DCR (e.g. $\lambda=0.12$ or $\lambda=0.21$ ) Table 3. Results for the case with downtime cost ratio 0.12 for EPCLP compared to constant CLP

\begin{tabular}{|c|c|c|c|c|c|c|c|c||}
\hline policy & $d_{1}$ & $d_{2}$ & Outages & CM & PM & OM & cost (\$/day) & cost-saving \\
\hline EPCLP & {$[-1,-1,0]$} & -1.1 & 11.7 & 1.3 & 14.0 & 3.2 & 890 & \multirow{2}{*}{$7 \%$} \\
\hline CLP & -0.5 & -1 & 9.8 & 2.2 & 8.0 & 5.6 & 960 & \\
\hline
\end{tabular}
and high DCR (e.g. $\lambda=0.35$ ), respectively. The reason for the difference of the optimal thresholds is that performing more PMs are cost-effective for cases with lower DCR while fewer

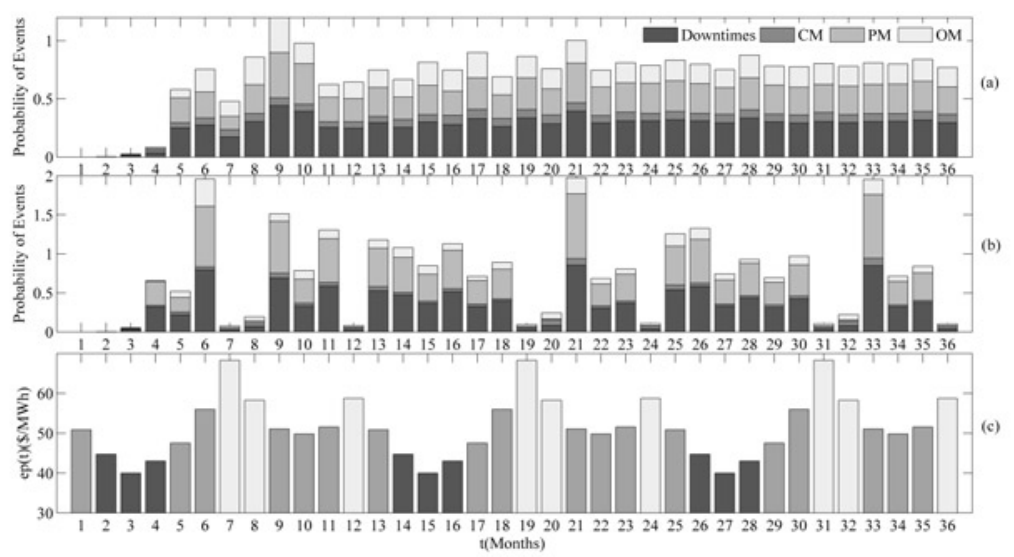

Fig. 4. Comparison of the event probability distributions between the and CLP a) and EPCLP b) and CIS the forecasting electricity price

\begin{abstract}
PMs are needed for cases with higher DCRs.
\end{abstract}

\section{2) Influence of reliability levels}

The threshold of the proposed policy can be influenced by the reliability of the multi-component system, as well as the DCR. In the sensitivity analysis of reliability levels to the PM threshold, five cases with different values of the scale parameter $\eta$ in the PHM model are tested. For case $\mathrm{R} 1$, the scaling parameter $\eta$ are [1000 1500 800] and for case R2, the scaling parameter $\eta$ are set to be [1000 1500800$] \times 2$, and so on. The higher the scale parameter $\eta$, the higher the reliability is.

For case R1 with $\lambda=0.12$, the optimal thresholds are $[-1,-1,0]$ (Table 5). Whereas, for cases with the higher reliability levels, e.g. $\mathrm{R} 2, \mathrm{R} 3, \mathrm{R} 4$, the optimal thresholds are $[-1.5,0$, case. Generally, the total cost for each PM (including PM cost and downtime cost) is much lower than the total cost for each failure (including $\mathrm{CM}$ cost and downtime cost). Therefore, it is cost-effective to reduce failures by performing more PMs compared to the CLP.

Furthermore, the comparison of the event probability distributions between the EPCLP and CLP is shown in Fig. 4. The vertical axis indicates the
Table 4. Optimal results of the EPCLP for mean price scenario with various downtime cost ratios

\begin{tabular}{|c|c|c|c|c|c|c|c|c|c||}
\hline$\lambda$ & $\boldsymbol{d}_{1}$ & $d_{2}$ & Outages & CM & PM & OM & $\begin{array}{c}\text { Cost of } \\
\text { EPCLP }\end{array}$ & $\begin{array}{c}\text { cost of } \\
\text { CLP }\end{array}$ & $\begin{array}{c}\text { cost } \\
\text {-saving }\end{array}$ \\
\hline 0.12 & {$[-0.5,-1,0]$} & -1.1 & 11.7 & 1.3 & 13.9 & 3.2 & 900 & 960 & $7 \%$ \\
\hline 0.21 & {$[-0.5,-1,0]$} & -1.1 & 10.9 & 1.5 & 12.8 & 3.0 & 1200 & 1240 & $3 \%$ \\
\hline 0.35 & {$[-1.5,0,0]$} & -2 & 8.4 & 2.7 & 9.9 & 11.5 & 1730 & 1810 & $4 \%$ \\
\hline$<0.5$ & -0.5 & -1 & 9.5 & 2.2 & 8.5 & 7.1 & & & \\
\hline
\end{tabular}


Table 5. Optimal results for the case with mean price scenario and $\lambda=0.12$ via the EPCLP

\begin{tabular}{||c|c|c|c|c|c|c|c||}
\hline \hline case & $d_{1}$ & $d_{2}$ & Outages & CM & PM & OM & cost (\$/day) \\
\hline R1 & {$[-1,-1,0]$} & -1.1 & 11.7 & 1.3 & 13.9 & 3.2 & 890 \\
\hline R2 & {$[-1.5,0,0]$} & -2 & 4.2 & 1.3 & 5.3 & 5.1 & 510 \\
\hline R3 & {$[-1.5,0,0]$} & -2 & 3.1 & 0.7 & 4.1 & 3.1 & 320 \\
\hline R4 & {$[-1.5,0,0]$} & -2 & 2.7 & 0.4 & 3.3 & 2.5 & 230 \\
\hline \hline
\end{tabular}
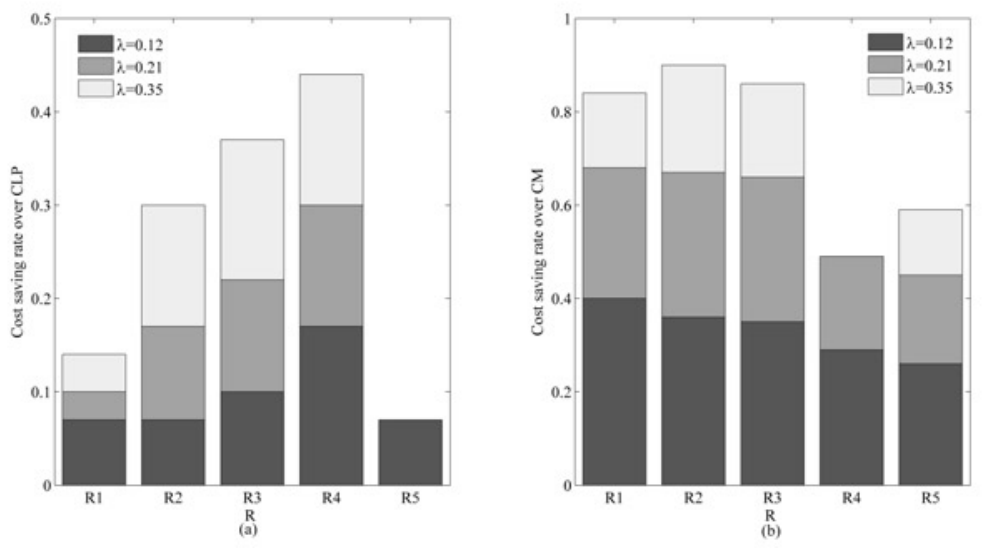

Fig. 5. Cost saving rate of EPCLP over CLP a) and CM b) for different reliabilities and DCRS

0]. Since fewer PMs are needed for latter cases, the threshold of the price level which has the minimal continuous price periods should be the minimum. Nevertheless, for the mean price scenario with low DCR (e.g. $\lambda=0.12$ ), more PMs are needed for cases with lower reliability levels. So for low reliability cases the optimal thresholds are $[-1,-1,0]$ while the optimal thresholds are $[-1.5,0,0]$ for high reliability cases. Since fewer PMs are needed as the reliability increases, the threshold is minimal during the price periods for which the number of continuous time periods is minimal. It is economical to perform fewer PMs for cases with higher reliability levels. And it is cost-efficient to set the threshold of the low price periods to be minimal since the continuous time periods ratio for different electricity price levels is $T_{\mathrm{cL}}: T_{\mathrm{cM}}: T_{\mathrm{cH}}=3: 9: 6$.

The cost-saving of the proposed policy over the constant CLP (or over the CM policy) for various downtime cost ratios and reliability levels are shown in Fig. 5(a) and Fig. 5(b), respectively. The results show that the proposed policy can provide a cost saving of about $3 \%$ to $17 \%$ over CLP for the cases with valid reliabilities (e.g. R1, R2 and R3) and DCRs (e.g. $\lambda \leq 0.35$ ). Whereas for cases with higher reliabilities (e.g. R4 and R5), the valid range of the DCR becomes much smaller, e.g. such as $\lambda \leq 0.21$ and $\lambda \leq 0.12$ for case R4 and case R5, respectively. For cases with higher reliabilities (e.g. R5) and higher DCR (e.g. $\lambda \geq 0.21$ ), the proposed policy can be no longer cost-effective than CLP since few PMs are needed.

\section{3) Influence of covariate processes}

To analyze the influence of the covariate on the performance of the proposed policy, the parameterized transition matrix is:

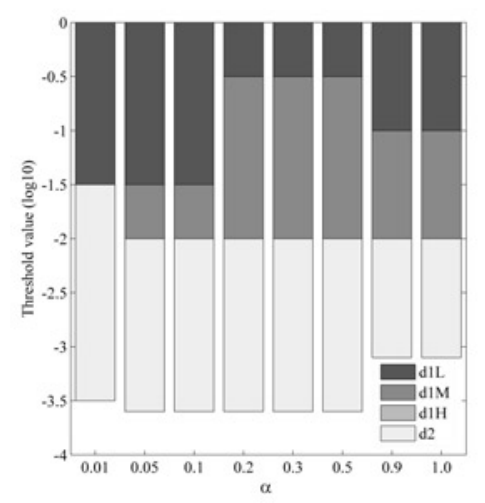

$$
M_{\alpha}=\left[\begin{array}{cccc}
1-\alpha & \alpha / 3 & \alpha / 3 & \alpha / 3 \\
\alpha / 3 & 1-\alpha & \alpha / 3 & \alpha / 3 \\
\alpha / 3 & \alpha / 3 & 1-\alpha & \alpha / 3 \\
0 & 0 & 0 & 1
\end{array}\right] .
$$

Compared to the CLP, the cost-saving rate of EPCLP generally decreases as the parameter $\alpha$ increases (Fig. 6). For example, in the case when $\alpha=0.01$ and $\lambda=0.12$, the cost-saving rate is $15 \%$, and it is reduced to $6 \%$ as $a$ is increased to 0.2 .

Since more PMs are needed as $a$ increases, the optimal price-dependent thresholds can be affected as a result. For example, when DCR is $\lambda=0.12$, the optimal price-dependent level-1 thresholds for $0.05 \leq \alpha<0.2$ and $0.2 \leq \alpha<0.9$ are $[-1.5,-0.5,0]$ and $[-0.5,-1.5,0]$, respectively. The changes of the optimal thresholds show that more PMs are needed for rapid covariate degradation.

The threshold of the average price periods is set to be lowest since the number of continuous middle price periods $\left(T_{\mathrm{cM}}\right)$ is the highest. From the relationships between the optimal thresholds and the price scenarios (more details are discussed in Section 3.3-4), the ratio for continuous periods of low, average, and high price $T_{\mathrm{cL}}: T_{\mathrm{cM}}: T_{\mathrm{cH}}$ is $3: 9: 6$. The changes in the optimal thresholds show that more PMs are needed

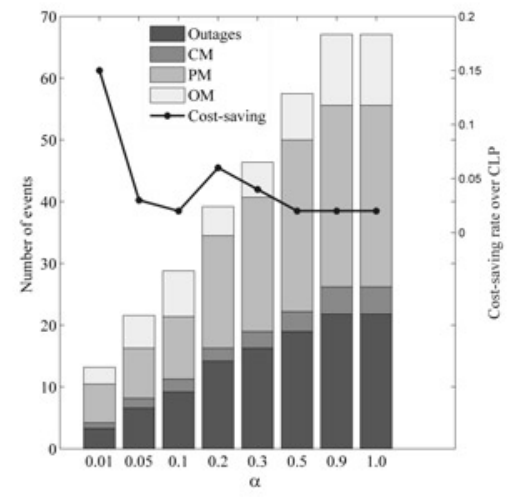

Fig. 6. Comparison of EPCLP and CLP in terms of degradation parameter alpha

for rapid covariate degradation. So the lowest threshold of the pricedependent thresholds is set during the average price periods since the number of continuous periods for the average price is the largest.

4) Influence of electricity price scenarios

For the electricity price-dependent control-limit policy, it is instructive to change the property of the electricity price scenario to analyze the influence of different price scenarios to the performance of the two policies.

From the results of the optimal thresholds for different price scenarios, there may exist specific relationships between the optimal thresholds and some specific properties of the electricity price process. To verify this conjecture, 13 typical price scenarios are selected from the total 59049 price scenarios (e.g. price scenario 00001, 01249, 01250, 04150, 06292, 31321, 31869, 48037, 58002, 58888, 58917,58937 and 59030 are the label for the forecasting electricity scenarios). The price scenarios can be generated and reduced by the scenario generation method [12]. 


\section{\begin{tabular}{l|l|l|l|l|l|l|l|l|l}
$\mathrm{L}$ & $\mathrm{L}$ & $\mathrm{M}$ & $\mathrm{M}$ & $\mathrm{M}$ & $\mathrm{L}$ & $\mathrm{H}$ & $\mathrm{M}$ & $\mathrm{M}$ & $\mathrm{L}$ \\
\hline
\end{tabular} \\ Planning Horizon

$$
T_{\mathrm{cL}}: T_{\mathrm{cM}}: T_{\mathrm{cH}}=3: 2: 1 \quad T_{\mathrm{sL}}: T_{\mathrm{sM}}: T_{\mathrm{sH}}=4: 5: 1
$$

Fig. 7. Schematic representation of continuous periods $C$ and cumulative periods $S$

To summarize the relationships between the optimal thresholds and the electricity price scenarios from the simulation results, some properties of the electricity price scenarios can be detected. Firstly, $T_{\mathrm{cL}}, T_{\mathrm{cM}}, T_{\mathrm{cH}}$ are defined to be the numbers of continuous periods for above-average price, average price and below-average price, respectively. Secondly, $T_{\mathrm{sL}}, T_{\mathrm{sM}}, T_{\mathrm{sH}}$ denote the sum of the periods for a low price level, an average price level and a high price level, respectively. As shown in Fig. 7, the ratio among the numbers of continuous periods for below-average price, average price and above-average price is $T_{\mathrm{cL}}: T_{\mathrm{cM}}: T_{\mathrm{cH}}=3: 2: 1$. Moreover, the ratio among the sum of the periods for a low price level, an average price level and a high price level is $T_{\mathrm{sL}}: T_{\mathrm{SM}}: T_{\mathrm{sH}}=4: 5: 1$.

The relationships between the optimal thresholds and price scenarios (Table 6) are summed up from the optimal thresholds of various price scenarios. The relationship between the optimal thresholds and price scenarios can be summarized in terms of different DCRs.

(1) Various price scenarios with low DCRs and low reliabilities;

For the cases with lower DCRs (e.g. $\lambda<0.2)$ and lower reliabilities (e.g. case R1), more PMs are needed to be performed. The relationship between the optimal thresholds and the price scenarios can be divided into three categories.

For the category (a) (e.g. scenario 00001, 58888, 58917, 58937, 59030), the minimal threshold can be assigned to the price levels which achieve the highest number of continuous price periods $\max \left[T_{\mathrm{cL}}, T_{\mathrm{cM}}\right.$, $\left.T_{\mathrm{cH}}\right]$. For the price scenario 00001 , the largest number of continuous price periods is the average price, i.e. $\max \left[T_{\mathrm{cL}}, T_{\mathrm{cM}}, T_{\mathrm{cH}}\right]=\max [6,9$, $3]=T_{\mathrm{cM}}$, the minimal threshold can be assigned to the average price levels, i.e. $\min \left[d_{1 \mathrm{~L}}, d_{1 \mathrm{M}}, d_{1 \mathrm{H}}\right]=d_{1 \mathrm{M}}$.

For the category (b) (e.g. scenario 04150, 06292, 31321, 48037), for the price level which achieves the highest number of continuous price periods, and the sum of the corresponding price periods is relatively much higher than other price levels, the minimal thresholds can

Table 6. Specific relationships between the price scenarios and optimal thresholds via the price-dependent control-limit policy for case R1

\begin{tabular}{|c|c|c|c|c|c|c|c|c|c|}
\hline \multirow{2}{*}{$\begin{array}{l}\text { cat- } \\
\text { egory }\end{array}$} & \multirow{2}{*}{$\begin{array}{c}\text { price } \\
\text { scenario }\end{array}$} & \multirow{2}{*}{$T_{\mathrm{cL}}$} & \multirow{2}{*}{$T_{\mathrm{CM}}$} & \multirow{2}{*}{$T_{\mathrm{cH}}$} & \multirow{2}{*}{$T_{\mathrm{sL}}$} & \multirow{2}{*}{$T_{\mathrm{sM}}$} & \multirow{2}{*}{$T_{\mathrm{sH}}$} & \multicolumn{2}{|c|}{$\min \left[d_{1 L}, d_{1 \mathrm{M}}, d_{1 \mathrm{H}}\right]$} \\
\hline & & & & & & & & $\lambda<0.2$ & $\lambda \geq 0.2$ \\
\hline \multirow{5}{*}{ a } & 00001 & 6 & 9 & 3 & 24 & 9 & 3 & $d_{1 \mathrm{M}}$ & $d_{1 \mathrm{M}}$ \\
\hline & 58888 & 6 & 9 & 3 & 18 & 9 & 9 & $d_{1 \mathrm{M}}$ & $d_{1 \mathrm{M}}$ \\
\hline & 58937 & 3 & 9 & 6 & 9 & 9 & 18 & $d_{1 \mathrm{M}}$ & $d_{1 \mathrm{M}}$ \\
\hline & 58917 & 6 & 9 & 6 & 12 & 12 & 12 & $d_{1 \mathrm{M}}$ & $d_{1 \mathrm{~L}}$ \\
\hline & 59030 & 3 & 9 & 6 & 9 & 9 & 18 & $d_{1 \mathrm{M}}$ & $d_{1 \mathrm{~L}}$ \\
\hline \multirow{4}{*}{ b } & 04150 & 3 & 7 & 3 & 9 & 18 & 9 & $d_{1 \mathrm{H}}, d_{1 \mathrm{~L}}$ & $d_{1 \mathrm{~L}}$ \\
\hline & 06292 & 3 & 7 & 3 & 9 & 15 & 12 & $d_{1 \mathrm{H}}, d_{1 \mathrm{~L}}$ & $d_{1 \mathrm{~L}}$ \\
\hline & 31321 & 3 & 7 & 3 & 9 & 18 & 9 & $d_{1 \mathrm{H}}, d_{1 \mathrm{~L}}$ & $d_{1 \mathrm{~L}}$ \\
\hline & 48037 & 3 & 7 & 3 & 9 & 18 & 9 & $d_{1 \mathrm{H}}, d_{1 \mathrm{~L}}$ & $d_{1 L}$ \\
\hline \multirow{4}{*}{ c } & 01249 & 6 & 10 & 3 & 15 & 18 & 3 & $d_{1 \mathrm{~L}}$ & $d_{1 \mathrm{~L}}$ \\
\hline & 01250 & 6 & 12 & 6 & 15 & 15 & 6 & $d_{1 \mathrm{~L}}$ & $d_{1 \mathrm{~L}}$ \\
\hline & 31869 & 6 & 12 & 6 & 12 & 12 & 12 & $d_{1 \mathrm{~L}}$ & $d_{1 \mathrm{~L}}$ \\
\hline & 58002 & 6 & 12 & 6 & 12 & 12 & 12 & $d_{1 \mathrm{~L}}$ & $d_{1 \mathrm{~L}}$ \\
\hline
\end{tabular}

be assigned to the other price levels. For the price scenario 04150, the largest number of continuous price periods is the average price, i.e. $\max \left[T_{\mathrm{cL}}, T_{\mathrm{cM}}, T_{\mathrm{cH}}\right]=\max [3,7,3]=T_{\mathrm{cM}}$. And the sum of the periods for different price levels are $\left[T_{\mathrm{sL}}, T_{\mathrm{sM}}, T_{\mathrm{sH}}\right]=[9,18,9]$. The sum of the periods for average price level $\left(T_{\mathrm{SM}}=18\right)$ is much larger than that of low and high price levels. If a minimal threshold is assigned to the average price level, much more PMs can be performed since $T_{\mathrm{sM}}$ is much higher than $T_{\mathrm{sL}}$ and $T_{\mathrm{sH}}$. As a result, too much PMs will be performed and the maintenance cost can be increased. So it will be cost effective to perform PM during the low and high price periods instead of during the average price periods for price scenario 04150 .

For the category (c) (e.g. scenario $01249,01250,31869,58002$ ), the largest continuous price periods $\max \left[T_{\mathrm{cL}}, T_{\mathrm{cM}}, T_{\mathrm{cH}}\right]$ are much higher than other price levels, the minimal thresholds can be assigned to the price levels with second largest continuous price periods. For the price scenario 01250 , the largest number of continuous price periods is the average price, i.e. $\max \left[T_{\mathrm{cL}}, T_{\mathrm{cM}}, T_{\mathrm{cH}}\right]=\max [6,12,6]=12=T_{\mathrm{cM}}$, then $\min \left[d_{1 \mathrm{~L}}, d_{1 \mathrm{M}}, d_{1 \mathrm{H}}\right]$ can be assigned to the low price level.

(2) Various price scenarios with higher DCRs (e.g. $\lambda \geq 0.2)$ or higher reliabilities.

For the cases with higher downtime cost ratios (e.g. $\lambda \geq 0.2$ ) or higher reliabilities of the multi-component system (e.g. case R2), fewer PMs are needed. So the minimal threshold can be assigned to the price levels which have the lowest continuous price periods (e.g. scenario $01249,1250,04150,06293,31321,31869,48037,58002$, 58917 and 59030) or the second lowest continuous price periods (e.g. scenario 00001, 58888 and 58937).

\section{Conclusions}

This paper has proposed an electricity price-dependent controllimit policy (EPCLP) for the power generating unit taking into account the electricity price-dependent downtime cost for CBM. Since the proposed EPCLP can take full advantage of the changes of the fluctuating electricity prices, it can make further maintenance cost reduction in comparison of the constant control-limit policy. From the extensive computational analysis, it can be concluded that the EPCLP holds a significant advantage of cost-saving if the downtime cost rates, reliabilities of the multi-component system and the covariate are among the valid ranges. Future extensions of this work will focus on the investigating optimal CBM policy for complex multi-component system that build on our control-limit policy. In addition, although we assume the forecasting electricity is deterministic, it is also possible to consider the case in which the forecasting electricity is of uncertainty.

\section{Acknowledgement}

This work is supported by National Natural Science Foundation of China (Grant No. 71501148, 51379081). The research work is also supported by the Key Laboratory of Metallurgical Equipment and Control of Education Ministry of Wuhan University of Science and Technology (Grant No. 2015B05). 


\section{References}

1. Ahmad R, Kamaruddin S. An overview of time-based and condition-based maintenance in industrial application. Computers \& Industrial Engineering 2012; 63(1): 135-149, http://dx.doi.org/10.1016/j.cie.2012.02.002.

2. Banjevic D, Jardine AKS, Makis V, Ennis M. A control-limit policy and software for condition-based maintenance optimization. INFOR 2001; 39(1): 32-50.

3. Castanier B, Grall A, Berenguer C. A condition-based maintenance policy with non-periodic inspections for a two-unit series system. Reliability Engineering \& System Safety 2005; 87(1): 109-120, http://dx.doi.org/10.1016/j.ress.2004.04.013.

4. Chen A. and Wu G. Real-time health prognosis and dynamic preventive maintenance policy for equipment under aging Markovian deterioration. International Journal of Production Research 2007; 45(15): 3351-3379, http://dx.doi.org/10.1080/00207540600677617.

5. Chen D, Trivedi K S. Optimization for condition-based maintenance with semi-Markov decision process. Reliability Engineering \& System Safety 2005; 90(1): 25-29, http://dx.doi.org/10.1016/j.ress.2004.11.001.

6. Cox D. Regression models and life-tables. Journal of the Royal Statistical Society. Series B (Methodological) 1972; 34(2): 187-220.

7. Diyin T, Jinsong Y. Optimal Replacement Policy for a Periodically Inspected System Subject to the Competing Soft and Sudden Failures. Eksploatacja i Niezawodnosc - Maintenance and Reliability 2015; 17(2): 228-235, http://dx.doi.org/10.17531/ein.2015.2.9.

8. Elwany A H, Gebraeel N Z, Maillart L M. Structured Replacement Policies for Components with Complex Degradation Processes and Dedicated Sensors. Operations Research 2011; 59(3): 684-695, http://dx.doi.org/10.1287/opre.1110.0912.

9. Gorjian N, Ma L, Mittinty M, Yarlagadda P, Sun Y. A review on degradation models in reliability analysis, in Proceedings of the 4th World Congress on Engineering Asset Management 2009. Athens.

10. Gröwe-Kuska N, Kiwiel K, Nowak M, Nowak M P, Römisch W, Wegner I. Power management under uncertainty by Lagrangian relaxation. in Proceedings of the 6th International Conference Probabilistic Methods Applied to Power Systems PMAPS 2000. INESC Porto.

11. Hamilton J D. Time series analysis. New York: Cambridge Univ Press, 1994.

12. Heitsch H, Römisch W. Scenario reduction algorithms in stochastic programming. Computational optimization and applications 2003; 24(2): 187-206, http://dx.doi.org/10.1023/A:1021805924152.

13. Jardine A K S, Makis V, Banjevic D, Braticevic D, Ennis M. A decision optimization model for condition-based maintenance. Journal of Quality in Maintenance Engineering 1998; 4(2): 115-121, http://dx.doi.org/10.1108/13552519810213644

14. Jardine A K S, Lin D, and Banjevic D. A review on machinery diagnostics and prognostics implementing condition-based maintenance. Mechanical Systems and Signal Processing 2006; 20(7): 1483-1510, http://dx.doi.org/10.1016/j.ymssp.2005.09.012.

15. Jiang R. A multivariate CBM model with a random and time-dependent failure threshold. Reliability Engineering \& System Safety 2013; 119: 178-185, http://dx.doi.org/10.1016/j.ress.2013.05.023.

16. Jiang R. Optimization of alarm threshold and sequential inspection scheme. Reliability Engineering \& System Safety 2010; 95(3): 208-215, http://dx.doi.org/10.1016/j.ress.2009.09.012.

17. Liu Q, Dong M, Lv W, Geng X, Li Y. A novel method using adaptive hidden semi-Markov model for multi-sensor monitoring equipment health prognosis. Mechanical Systems and Signal Processing 2015; 64-65: 217-232, http://dx.doi.org/10.1016/j.ymssp.2015.03.029.

18. Makis V, Jardine A K S. Optimal replacement in the proportional hazards model. INFOR 1992; 30(1): 172-183.

19. Makis V, Jiang X. Optimal Replacement Under Partial Observations. Mathematics of Operations Research 2003; 28(2): 382-394, http:// dx.doi.org/10.1287/moor.28.2.382.14484.

20. Marseguerra M, Zio E, Podofillini L. Condition-based maintenance optimization by means of genetic algorithms and Monte Carlo simulation. Reliability Engineering \& System Safety 2002; 77(2): 151-165, http://dx.doi.org/10.1016/S0951-8320(02)00043-1.

21. PJM. Hourly Real-Time \& Day-Ahead LMP. [cited 2014; Available from: http://www.pjm.com/markets-and-operations/energy/real-time/ onthlylmp.aspx.

22. Qian X. Control-limit Policy of Condition-based Maintenance Optimization for Multi-component System by Means of Monte Carlo Simulation. IAENG International Journal of Computer Science 2014; 41(4): 269-273.

23. Tian Z, Liao H. Condition based maintenance optimization for multi-component systems using proportional hazards model. Reliability Engineering \& System Safety 2011; 96(5): 581-589, http://dx.doi.org/10.1016/j.ress.2010.12.023.

24. Wang W. A model to determine the optimal critical level and the monitoring intervals in condition-based maintenance. International Journal of Production Research 2000; 38(6): 1425-1436, http://dx.doi.org/10.1080/002075400188933.

25. Yang K, Yang G. Degradation Reliability Assessment Using Severe Critical Values. International Journal of Reliability, Quality and Safety Engineering 1998; 5(1): 85-95, http://dx.doi.org/10.1142/S0218539398000091.

26. Zhao X, Fouladirad M, Bérenguer C, Bordes L. Condition-based inspection/replacement policies for non-monotone deteriorating systems with environmental covariates. Reliability Engineering \& System Safety 2010; 95(8): 921-934, http://dx.doi.org/10.1016/j.ress.2010.04.005.

\section{Xinbo QIAN}

The Key Laboratory of Metallurgical Equipment and

Control of Education Ministry

Wuhan University of Science and Technology

No. 947 Heping Avenue, Wuhan 430081, China

Yonggang WU

School of Hydropower and Information Engineering

Huazhong University of Science and Technology

No. 1037 Luoyu road, Wuhan 430074, China

E-mails:xinboqian@wust.edu.cn,ygangwu@163.com 